\title{
HUBUNGAN IKLIM SEKOLAH DENGAN MOTIVASI KERJA GURU
}

\author{
Sukron Fujiaturrahman \\ Dosen PGSD, FKIP Universitas Muhammadiyah Mataram \\ sukronfu27@gmail.com
}

\section{INFO ARTIKEL}

Riwayat Artikel:

Diterima: $16-12-2017$

Disetujui: 02 - $01-2018$

\section{Kata Kunci:}

1. Iklim Sekolah

2. Motivasi Kerja Guru

\begin{abstract}
ABSTRAK
Abstrak: Penelitian ini adalah sebuah penelitian korelasional yang bertujuan untuk menemukan hubungan iklim sekolah dengan motivasi kerja guru. Suasana lingkungan kerja yang dirasakan para guru kerap berubah dan hal itu berdampak terhadap motivasi kerja guru. Berdasarkan hipotesis yang telah dirumuskan, iklim sekolah diasumsikan berhubungan dengan motivasi kerja guru. Penelitian ini menggunakan metode survey, 30 orang guru di SDN segugus 07 dipilih secara acak. Instrumen yang digunakan berupa kuesioner. Verifikasi hipotesis dilakukan dengan analisis regresi melalui uji $\mathrm{F}$ dan menemukan model persamaan regresi, dan koefisien korelasi antara variabel iklim sekolah dengan motivasi kerja guru. Hasil penelitian menunjukkan bahwa hubungan antara iklim sekolah dengan motivasi kerja guru adalah .886 ( $\alpha .05)$. Dapat disimpulkan bahwa iklim sekolah berkontribusi dengan motivasi kerja guru. Dengan mempertimbangkan temuan penelitian tersebut, maka diharapkan Kepala sekolah dan guru senantiasa menjaga iklim sekolah agar tetap kondusif, baik dari segi fisik maupun non fisik, sehingga para guru akan merasa nyaman dan tetap bersemangat dalam bekerja dan tentu sekali hal tersebut juga akan berdampak kepada seluruh peserta didik.
\end{abstract}

\section{A. LATAR BELAKANG}

Salah satu unsur penting dalam pendidikan adalah guru. Guru merupakan salah satu komponen manusia dalam proses belajar-mengajar, yang ikut berperan dalam usaha pembentukan sumber daya manusia yang potensial di bidang pembangunan (Sardiman A.M., 2014:125). Guru sangat berperan dalam membantu perkembangan peserta didik untuk mewujudkan tujuan hidupnya secara optimal. Kemampuan, bakat, dan minat peserta didik tidak akan berkembang secara optimal tanpa adanya bantuan guru. Gurulah yang pertama kali memperkenalkan huruf-huruf dan angka-angka sehingga peseta didik menjadi bisa membaca dan berhitung. Guru pula yang mengajarkan memengang pensil sehingga peserta didik bisa menulis. Guru pula yang memberi dorongan agar peserta didik berani berbuat benar, dan membiasakan mereka untuk bertanggung jawab terhadap perbuatannya.

Dalam melaksanakan berbagai tugas sebagai seorang guru yang setiap hari bertemu dan berinteraksi dengan peserta didik, dan warga sekolah lainnya, guru terkadang merasa sangat bersemangat, rajin dan disiplin. Terkadang juga merasa malas, tidak bersemangat, jenuh atau bosan dalam menjalankan tugasnya sebagai guru. Semua itu indikasi bahwa sudah terjadi perubahan energi dari dalam diri guru tersebut atau disebut dengan istilah motivasi.
Menurut Kreitner dan Kinicki (2014:212) istilah motivasi berasal dari kata latin movere, yang berarti "menggerakkan". Dalam konteks masa kini, motivasi mempresentasikan proses-proses psikologis yang menyebabkan stimulasi, arahan, dan kegigihan terhadap sebuah kegiatan yang dilakukan secara sukarela yang diarahkan pada suatu tujuan.

Santrock (2011:438) mengunggkapkan bahwa motivasi melibatkan proses-proses yang mengaktifkan, mengarahkan dan mempertahankan perilaku. Oleh karena itu, individu yang termotivasi adalah individu yang perilakunya diaktifkan, diarahkan, dan dipertahankan. Motivasi ada dua yaitu, motivasi instrinsik dan ekstrinsik. Motivasi intrinsik timbul dari dalam diri individu sendiri tanpa ada paksaan dorongan orang lain, tetapi atas dasar kemauan sendiri. Sedangkan motivasi ekstrinsik timbul sebagai akibat pengaruh dari luar individu, apakah karena adanya ajakan, suruhan atau paksaan dari orang lain sehingga dengan keadaan demikian seseorang mau melakukan sesuatu.

Kompri (2015:65) mengemukakan bahwa motivasi kerja adalah sesuatu yang dapat menimbulkan semangat atau dorongan bekerja individu atau kelompok terhadap pekerjaan guna mencapai tujuan. Motivasi kerja guru adalah kondisi yang membuat guru mempunyai kemauan/kebutuhan untuk mencapai tujuan tertentu melalui pelaksanaan suatu tugas. Motivasi guru akan 
menyuplai energi untuk bekerja/mengarahkan aktivitas selama bekerja, dan menyebabkan seorang guru mengetahui adanya tujuan yang relevan antara tujuan organisasi dan tujuan pribadinya. Dengan demikian dapat dikatakan semakin tinggi motivasi seseorang maka semakin tinggi pula kinerjanya, begitu pula sebaliknya semakin rendah motivasi seseorang maka semakin rendah pula kinerjanya.

Tinggi rendahnya motivasi kerja guru tentu sekali dipengaruhi oleh berbagai faktor yang ada dalam diri guru maupun di luar diri guru. Salah satu yang terkait dengan motivasi kerja guru adalah iklim sekolah. Iklim sekolah merupakan suasana lingkungan sekolah, baik fisik atau nonfisik, yang dirasakan oleh orang-orang yang berada di sekolah yakni guru, peserta didik, dan warga sekolah lainya. Suasana fisik berkenaan dengan suasana ruangan atau tempat untuk pembelajaran siswa baik di kelas, perpustakaan maupun di laboratorium. Bila suasan ruangan dirasakan kondusif atau nyaman dan tidak terganggu oleh kebisingan di luar ruangan, guru dan peserta didik akan lebih bertahan lama dan tidak cepat jenuh atau bosan untuk melaksanakan proses pembelajaran. Dengan iklim sekolah yang kondusif dan mendukung akan meningkat kepercayaan diri seseorang dalam melaksanakan dan menyelesaikan tugas yang diberikan sehingga pada akhirnya seseorang akan menjadi termotivasi untuk segera mencapai tujuan yang telah ditentukan.

Sekolah merupakan satu institusi. Sebuah institusi juga dipandang sebagai satu organisasi. Iklim sekolah merupakan implikasi dari iklim organisasi yang dikaitkan dengan lingkungan sekolah yakni tempat guru-guru melakukan aktivitasnya. Menurut Davis dan Newstrom (1996:24) iklim organisasi menunjukkan cara hidup suatu organisasi. Iklim organisasi dapat menimbulkan pengaruh besar terhadap motivasi, prestasi, dan kepuasan kerja pegawai. Iklim timbul dari sistem perilaku organisasi yang mencakup filsafat dan tujuan, kepemimpinan, organisasi formal dan informal, dan lingkungan sosial.

Kompri (2014:299) mendifinisikan iklim sebagai efekefek perasaan subjektif dari sistem manajer formal atau informal, dan berbagai faktor lingkungan yang lainnya yang berpengaruh terhadap sikap kepercayaan, nilai dan motivasi orang-orang yang bekerja dalam organisasi tertentu. Dengan demikian, iklim sekolah berarti berkenaan dengan keberadaan dan suasana lingkungan sekolah yang dirasakan orang-orang yang berada di sekolah. Sebagaimana yang diungkapkan oleh Loukas (2007) bahwa iklim sekolah berkenaan dengan perasaan dan sikap yang ditimbulkan oleh lingkungan sekolah..

\section{B. METODE PENELITIAN}

Pendekatan yang digunakan dalam penelitian ini adalah pendekatan kuantitatif dengan metode survey (studi korelasional) yang menggambarkan tentang variabel- variabel yang diteliti, sekaligus menyelidiki hubungan antar variabel. Penelitian ini bertujuan untuk mengetahui Hubungan iklim sekolah dengan motivasi kerja guru di SDN segugus 07 Praya Timur, Kabupaten Lombok Tengah. Sampel dipilih dengan menggunakan purposive random sampling dan ditetapkan jumlah sampel sebanyak 30 orang guru di SDN segugus 07 Praya Timur.

Pengumpulan data dengan menggunakan kuesioner atau angket untuk masing-masing variabel. Selanjutnya, untuk mendapatkan data yang sahih maka instrumen tersebut diuji pakar dan dilanjutkan dengan validitas empiris, untuk menguji validitas dengan menggunakan rumus pearson product moment dan menghitung reliabilitas dengan menggunakan Alpha Cronbach.

Analisis data dalam penelitian ini meliputi analisis statistika deskriptif dan inferensial. Pengujian hipotesis dilakukan melalui uji $\mathrm{F}$ regresi sederhana dan ganda, dan uji korelasi untuk mengetahui kekuatan hubungan antar variabel setelah melalui uji normalitas menggunakan galat taksiran dan uji homogenitas menggunakan uji Barlett.

\section{HASIL DAN PEMBAHASAN}

Hasil penelitian yang diperoleh setelah dinyatakan memenuhi persyaratan analisis statistik, maka dilanjutkan dengan pengujian hipotesis dan mendapatkan data sebagai berikut:

\section{a) Regresi Sederhana Motivasi Kerja (Y) atas Iklim Sekolah (X)}

Hasil dari perhitungan regresi sederhana variabel motivasi kerja guru (Y) dengan iklim sekolah (X) dilakukan menggunakan program aplikasi statistik SPSS Versi 20.00 adalah sebagai berikut ini :

\section{Tabel 1}

\section{Regresi Y atas X (Sederhana)}

\section{Coefficients ${ }^{\mathrm{a}}$}

\begin{tabular}{|c|c|c|c|c|c|c|c|c|}
\hline \multirow[t]{2}{*}{ Model } & \multicolumn{2}{|c|}{$\begin{array}{l}\text { Unstand } \\
\text { ardized } \\
\text { Coefficie } \\
\text { nts }\end{array}$} & \multirow{2}{*}{\begin{tabular}{|c|}
$\begin{array}{c}\text { Standa } \\
\text { rdized } \\
\text { Coeffici } \\
\text { ents }\end{array}$ \\
Beta \\
\end{tabular}} & \multirow[t]{2}{*}{$\mathrm{t}$} & \multirow[t]{2}{*}{$\begin{array}{l}\text { Si } \\
\text { g. }\end{array}$} & \multicolumn{3}{|c|}{ Correlations } \\
\hline & B & $\begin{array}{l}\text { Std } \\
\text { Err } \\
\text { or }\end{array}$ & & & & $\begin{array}{c}\text { Zer } \\
\text { o- } \\
\text { ord } \\
\text { er }\end{array}$ & $\begin{array}{l}\mathrm{Pa} \\
\mathrm{rti} \\
\mathrm{al}\end{array}$ & $\begin{array}{c}\mathrm{Pa} \\
\mathrm{rt}\end{array}$ \\
\hline $\begin{array}{l}\text { (Consta } \\
\text { nt) } \\
1 \\
\text { Iklim_Se } \\
\text { kolah }\end{array}$ & $\begin{array}{r}96 \\
8\end{array}$ & $\begin{array}{r}, 06 \\
6\end{array}$ & 941, & $\begin{array}{r}, 74 \\
5 \\
14, \\
75 \\
3\end{array}$ & $\begin{array}{r}, 4 \\
6 \\
2 \\
, 0 \\
0 \\
0\end{array}$ & $\begin{array}{r}94 \\
1\end{array}$ & $\begin{array}{r}94 \\
1\end{array}$ & $\begin{array}{r}94 \\
1\end{array}$ \\
\hline
\end{tabular}

a. Dependent Variable: Motivasi_Kerja 
Berdasarkan hasil perhitungan regresi sederhana yang dilakukan, maka di kolom B diperoleh konstanta a sebesar 4,616 dan b sebesar 0,968 bentuk persamaan regresi linear sederhana yaitu : $\hat{Y}=4,616+0,968 X$.

Model hubungan antara iklim sekolah dan motivasi kerja guru dengan persamaan regresi $\hat{Y}=4,616+0,968 X$ dapat di tampilkan pada gambar berikut ini:

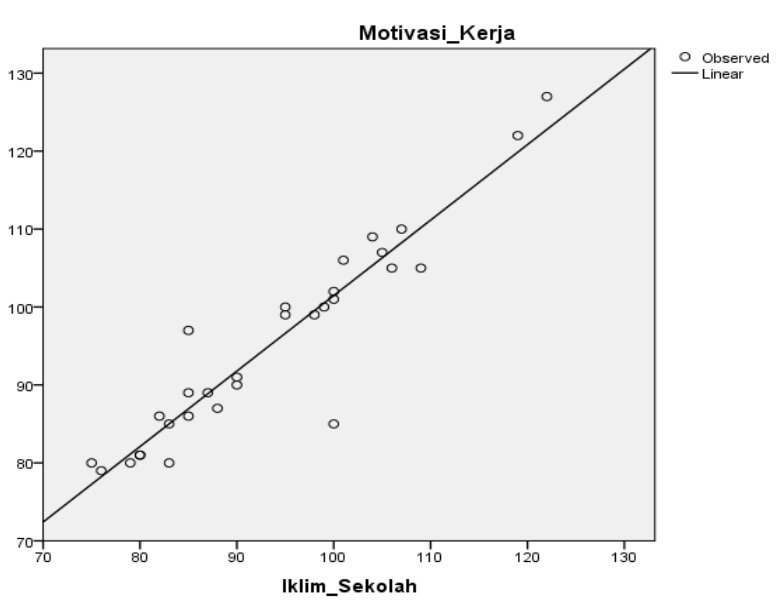

Gambar 1

\section{Grafik Hubungan antara Iklim Sekolah denganMotivasi Kerja Guru}

Dari persamaan regresi tersebut terlihat bahwa pengaruh iklim sekolah dengan motivasi kerja guru SDN seGugus 07 Praya Timur adalah searah (positif), hal tersebut ditunjukan pada koefisien regresi atau nilai b dalam persamaan regresi tersebut yang menunjukan angka positif sebesar 0,968 yang mengandung arti bahwa setiap kenaikan iklim sekolah 1 satuan akan diikuti dengan kenaikan motivasi kerja sebesar 0,968 satuan. Demikian pula sebaliknya, jika iklim sekolah mengalami penurunan 1 satuan maka motivasi kerja guru cenderung mengalami penurunan sebesar 0,968 satuan. Dan nilai koefisien a (intercept) sebesar 4,616 yang mempunyai arti apa bila tidak terdapat iklim sekolah $(X=0)$ diperkirakan motivasi kerja guru sebesar 4,616 satuan.

Pada tabel koefisien yang telah dipaparkan pada bagian regresi sederhana di atas diperoleh $t_{\text {hitung }}=14,753$ pada taraf signifikan $\alpha=0,05$ untuk uji kedua belah pihak maka didapati $\mathrm{df}$ atau $\mathrm{dk}$ (drajat kebebasan)= 30-2, sehingga $t_{\text {tabel }}=1,701$.

Ternyata hasil perhitungan nilai $t_{\text {hitung }}>t_{\text {tabel }}$ atau 14,753> 1,701 dan menunjukan probabilitas signifikansi $0,000<0,5$ maka $\mathrm{H}_{0}$ ditolak dan $\mathrm{H}_{1}$ diterima artinya data hubungan positif yang signifikan antara iklim sekolah dengan motivasi kerja guru SDN se-Gugus 07 Praya Timur, Kabupaten Lombok Tengah.

b) Uji Signifikansi Persamaan Regresi Motivasi Kerja (Y) atas Iklim Sekolah (X)

Hasil dari perhitungan uji signifikansi persamaan regresi antara variabel hasil motivasi kerja guru (Y) dengan iklim sekolah (X) dilakukan menggunakan program aplikasi statistik SPSS Versi 20.00 adalah sebagai berikut ini :

Tabel 2

Uji Signifikansi Persamaan Regresi Y atas X ANOVAa

\begin{tabular}{|l|r|r|r|r|r|}
\hline Model & $\begin{array}{c}\text { Sum of } \\
\text { Squares }\end{array}$ & df & $\begin{array}{c}\text { Mean } \\
\text { Square }\end{array}$ & F & Sig. \\
\hline $\begin{array}{l}\text { Regressi } \\
\text { on }\end{array}$ & 4137,580 & 1 & 4137,580 & 217,6 &, 00 \\
Residual & 532,287 & 28 & 19,010 & & $0^{\mathrm{b}}$ \\
Total & 4669,867 & 29 & & & \\
\hline
\end{tabular}

a. Dependent Variable: Motivasi_Kerja

b. Predictors: (Constant), Iklim_Sekolah

Dari hasil analisis yang disajikan pada tabel ANOVAa di atas diperoleh, harga statistik $F_{\text {hitung }}=217,650$, dan $p$ value $=0.000<0,05$ hal ini berarti $\mathrm{H}_{0}$ ditolak. Artinya terdapat pengaruh linear variabel iklim sekolah dengan motivasi kerja guru.

\section{c) Korelasi Sederhana Iklim Sekolah (X) dengan Motivasi Kerja (Y)}

Hasil dari perhitungan korelasi variabel iklim sekolah (X) dengan motivasi kerja guru (Y) dilakukan menggunakan program aplikasi statistik SPSS Versi 20.00 adalah sebagai berikut:

Tabel 3

Korelasi X atas Y (Sederhana)

Correlations

\begin{tabular}{|c|c|c|c|}
\hline & & $\begin{array}{c}\text { Motivasi } \\
\text { Kerja }\end{array}$ & $\begin{array}{c}\text { Iklim_Sek } \\
\text { olah }\end{array}$ \\
\hline \multirow[t]{2}{*}{$\begin{array}{c}\text { Pearson } \\
\text { Correlation }\end{array}$} & $\begin{array}{c}\text { Motivasi_ } \\
\text { Kerja }\end{array}$ & 1,000 & ,941 \\
\hline & $\underset{\text { lah }}{\text { Iklim_Seko }}$ & 941 & 1,000 \\
\hline \multirow[t]{2}{*}{ Sig. (1-tailed) } & $\begin{array}{c}\text { Motivasi_ } \\
\text { Kerja }\end{array}$ & . & ,000 \\
\hline & $\begin{array}{c}\text { Iklim_Seko } \\
\text { lah }\end{array}$ & ,000 & . \\
\hline \multirow[t]{2}{*}{$\mathrm{N}$} & $\begin{array}{c}\text { Motivasi_ } \\
\text { Kerja }\end{array}$ & 30 & 30 \\
\hline & $\begin{array}{c}\text { Iklim_Seko } \\
\text { lah }\end{array}$ & 30 & 30 \\
\hline
\end{tabular}

Dari perhitungan korelasi sederhana di atas, maka diperoleh $r$ sebesar 0,941. Dari hasil tersebut dijelaskan angka 0,941 menunjukan kuatnya korelasi antara iklim sekolah dengan motivasi kerja guru karena nilai $r$ di atas 0,05 . Maka dapat disimpulkan bahwa koefisien korelasi sederhana antara hubungan iklim sekolah dengan motivasi kerja guru SDN se-Gugus 07 Praya Timur adalah kuat dan searah (Positif). 


\section{d) Koefisien Determinasi Iklim Sekolah (X) dan Motivasi Kerja (Y)}

Hasil dari perhitungan koefisien determinasi dari $\mathrm{R}$ Square dilakukan menggunakan program SPSS Versi 20.00 sebagai berikut ini :

Tabel 4

Koefisien Determinasi X atas Y

Model Summary

\begin{tabular}{|c|c|c|c|c|c|c|c|c|c|}
\hline \multirow{2}{*}{$\begin{array}{l}\text { Mo } \\
\text { del }\end{array}$} & \multirow[t]{2}{*}{$\mathrm{R}$} & \multirow{2}{*}{$\begin{array}{l}\mathrm{R} \\
\text { Squ } \\
\text { are }\end{array}$} & \multirow{2}{*}{$\begin{array}{c}\text { Adjus } \\
\text { ted R } \\
\text { Squar } \\
\text { e }\end{array}$} & \multirow{2}{*}{$\begin{array}{l}\text { Std. } \\
\text { Error } \\
\text { of the } \\
\text { Estima } \\
\text { te }\end{array}$} & \multicolumn{5}{|c|}{ Change Statistics } \\
\hline & & & & & $\begin{array}{l}\mathrm{R} \\
\text { Squa } \\
\text { re } \\
\text { Chan } \\
\text { ge }\end{array}$ & $\begin{array}{c}\text { F } \\
\text { Chan } \\
\text { ge }\end{array}$ & $\begin{array}{l}\mathrm{d} \\
\mathrm{f} \\
1\end{array}$ & $\begin{array}{l}d \\
f \\
2\end{array}$ & $\begin{array}{l}\text { Sig. } \\
\text { F } \\
\text { Cha } \\
\text { nge }\end{array}$ \\
\hline 1 & $\begin{array}{r}94 \\
1^{\mathrm{a}}\end{array}$ & $\begin{array}{r}\text {,88 } \\
\text { ren }\end{array}$ & 882, & 4,360 & 886, & $\begin{array}{r}217 \\
650\end{array}$ & & $\begin{array}{l}2 \\
8\end{array}$ & $\begin{array}{r}00 \\
0\end{array}$ \\
\hline
\end{tabular}

a. Predictors: (Constant), Iklim_Sekolah

Berdasarkan tabel perhitungan Koefisien determinasi di atas, maka R Square sebesar 0,886 atau 88,6. Hal ini menunjukan terdapat pengaruh positif dari iklim sekolah dengan motivasi kerja guru SDN se-Gugus 07 Praya Timur sebesar $88,6 \%$ sedangkan sisanya $11,4 \quad \%$ merupakan faktor lain.

Dengan merujuk kepada hasil perhitungan di atas maka hasil penelitian menunjukan bahwa terdapat hubungan positif dan signifikan antara iklim sekolah dan motivasi kerja guru hal ini ditunjukan dengan thitung $=$ jauh lebih besar pada ttabel pada taraf signifikan $\square=0,05$ yaitu 1.701 atau thitung 14,753 > 1,701.Pola hubungan antara kedua variabel ini dinyatakan oleh persamaan regresi $\hat{Y}=$ $4,616+0,968 X$. Persamaan ini menunjukan bahwa hubungan iklim sekolah dengan motivasi kerja guru adalah searah (positif), hal tersebut ditunjukan pada koefisien regresi atau nilai $\mathrm{b}$ dalam persamaan regresi tersebut yang menunjukan angka positif sebesar 0,968 yang mengandung arti bahwa setiap kenaikan variabel iklim sekolah 1 satuan akan diikuti dengan kenaikan variabel motivasi kerja guru sebesar 0,968 satuan, demikian pula sebaliknya. Dan nilai koefisien a (intercept) sebesar 4,616 yang mempunyai arti apa bila tidak terdapat variabel iklim sekolah diperkirakan motivasi kerja guru sebesar 4,616 satuan.

Selanjutnya pada tabel koefisien regresi sederhana diperoleh thitung $=14,753$ pada taraf signifikan $\square=0,05$ untuk uji kedua belah pihak maka didapati $\mathrm{df}$ atau $\mathrm{dk}$ (drajat kebebasan) $=30-2=$ sehingga ttabel $=1.701$. Hasil perhitungan nilai thitung $>$ ttabel atau 14,753 $>1,701$ dan menunjukan probabilitas signifikansi $0,000<0,5$ maka $\mathrm{H} 0$ ditolak dan $\mathrm{H} 1$ diterima artinya terdapat hubungan positif yang signifikan antara iklim sekolah dengan motivasi kerja guru SDN segugus 07 Praya Timur Kabupaten Lombok Tengah.

Hasil analisis korelasi sederhana antara iklim sekolah dengan motivasi kerja guru diperoleh $r$ sebesar 0,941 . Dari hasil tersebut dijelaskan angka 0,941 menunjukan kuatnya korelasi antara iklim sekolah dengan motivasi kerja guru karena nilai $r$ di atas 0,05. Maka dapat disimpulkan bahwa variabel iklim sekolah dengan motivasi kerja guru tersebut kuat dan searah (Positif).

Selanjutnya hasil analisis koefisien determinasi antara variabel iklim sekolah (X) dan motivasi krja guru (Y), maka R Square sebesar 0,886 atau 88,6\%. Hal ini menunjukan pengaruh positif dari iklim sekolah dengan motivasi kerja guru sebesar $88,6 \%$ sedangkan sisanya $11,4 \%$ merupakan faktor lain.

Berdasarkan hasil pengujian statistik tersebut menunjukan bahwa iklim sekolah memberikan konstribusi yang cukup signifikan terhadap motivasi kerja guru, dimana semakin tinggi iklim sekolah maka semakin tinggi pula motivasi kerja guru. Iklim sekolah adalah keadaan atau suasana lingkungan sekolah yang dirasakan oleh seluruh warga sekolah, baik dari lingkungan fisik maupun lingkungan nonfisik. Iklim organisasi sekolah yang kondusif sangat dibutuhkan bagi guru untuk menumbuhkan dorongan dalam diri guru tersebut untuk berkerja lebih bersemangat. Hal ini sesuai dengan yang di ungkapkan Keith Davis dan Jhon W. Newstrom bahwa iklim organisasi dapat menimbulkan pengaruh besar terhadap motivasi, prestasi, dan kepuasan kerja pegawai. Oleh karena itu dengan adanya iklim sekolah yang kondusif yang dirasakan oleh para guru, maka mereka akan selalu termotivasi dalam menjalankan setiap tugasnya.

\section{SIMPULAN DAN SARAN}

Berdasarkan hasil dan pembahasan di atas, diperoleh temuan bahwa terdapat hubungan positif antara iklim sekolah dengan motivasi kerja guru. Berdasarkan temuan penelitian di atas dapat disimpulkan bahwa variabel motivasi kerja guru sangat dihubungkan dengan variabel iklim sekolah karena variabel tersebut memiliki kontribusi yang signifikan terhadap motivasi kerja guru. Semakin akurat iklim sekolah, maka makin kuat motivasi kerja guru yang dimiliki, begitu juga sebaliknya. Oleh karena itu kepala sekolah dan guru senantiasa menjaga iklim sekolah agar tetap kondusif, baik dari segi fisik maupun non fisik, sehingga para guru akan merasa nyaman dan tetap bersemangat dalam bekerja dan tentu sekali hal tersebut juga akan berdampak kepada seluruh peserta didik.

\section{DAFTAR RUJUKAN}

[1] Davis, Keith dan Jhon W. Newstrom. Prilaku dalam Organisasi. Jakarta: Erlangga, 1996.

[2] Kompri. Motivasi Pembelajaran Perspektif Guru dan Siswa, Bandung: PT Remaja Rosdakarya:2015. 
[3] Kreitner dan Kinicki. Organizational Behavior Ninth Edition. New York: McGrow Hill, 2010.

[4] Kreitner dan Kinicki (alih bahasa Biro Bahasa alkemis). Perilaku Organisasi edisi sembilan, Jakarta: Salemba Empat, 2014.

[5] Loukas, Alexandra. What is School Climate?, Leadership Compass Vol. No.1,Fall2007,http://www.naesp.org/resources/2/Le adership_Compass/2007/LC2007v5n1a4.df (diakses 9 oktober 2015).

[6] Luthans, Fred. Organizational Behavior: An EvidenceBased Approach, New York: McGraw-Hill, 2011.

[7] Santrock, John W., Educational Psychology Fifth Edition, New York:McGraw-Hill, 2011. 